\title{
Telomerase reverse transcriptase induced thyroid carcinoma cell proliferation through PTEN/AKT signaling pathway
}

\author{
$\mathrm{HAO} \mathrm{ZHANG}^{1}$ and NING HU ${ }^{2}$ \\ ${ }^{1}$ The First Sector of Department of Thyroid Breast Surgery, Northern Branch of Jingmen No. 1 People's Hospital; \\ ${ }^{2}$ The Second Sector of Department of Thyroid Breast Surgery, Southern Branch of Jingmen No. 1 People's Hospital, \\ Jingmen, Hubei 448000, P.R. China
}

Received October 4, 2017; Accepted April 20, 2018

DOI: $10.3892 / \mathrm{mmr} .2018 .9119$

\begin{abstract}
Thyroid carcinoma is the most common endocrine malignant tumor in the world, and so, there is a requirement to develop novel molecular targets for thyroid cancer diagnosis and treatment. Telomerase reverse transcriptase (TERT) was revealed to promote cell proliferation in a number of types of cell. To evaluate whether and how TERT functioned on papillary thyroid cancer (PTC) cell proliferation, the present study constructed TERT over-expression [recombined (r)TERT plasmid group] and interference [small interfering RNA (si)-TERT group] models by liposome transfection respectively to study the molecular mechanisms. The transfection efficiency was first detected by reverse transcription-quantitative polymerase chain reaction (RT-qPCR) and western blotting to analyze TERT levels compared with the negative control (NC) and control groups. Then MTT and carboxyfluorescein diacetate succinimidyl ester assays were performed to determine living cell proliferation and total cell proliferation respectively. Propidium iodide assay was used to detect alterations in cell cycle progression. RT-qPCR and western blotting were performed to detect associated factor variation. The results demonstrated that, following the generation of TERT overexpression or silencing PTC cells, the living cells and also total cell proliferation increased significantly in the rTERT group, and decreased significantly in siTERT group, when compared with the NC and control groups. The cell cycle was accelerated in the rTERT group, and blocked in the G1/S transition in the siTERT group. The mRNA and protein levels of P27, P53 and phosphatase and tensin homolog (PTEN) decreased significantly in the
\end{abstract}

Correspondence to: $\mathrm{Dr} \mathrm{Ning} \mathrm{Hu}$, The Second Sector of Department of Thyroid Breast Surgery, Southern Branch of Jingmen No. 1 People's Hospital, 168 Xiangshan Avenue, Jingmen, Hubei 448000, P.R. China

E-mail: ningghu@163.com

Key words: telomerase reverse transcriptase, thyroid carcinoma, papillary thyroid cancer, cell proliferation, phosphatase and tensin homolog, protein kinase B
rTERP group and increased in the siTERP group, while cyclin dependent kinase 2 and Cyclin D1 increased significantly in the rTERP group and decreased in the siTERP group. The expression of cell division cycle $25 \mathrm{~A}$ did not alter significantly. The protein levels of $\beta$-catenin and retinoblastoma were also unaltered. Protein kinase B (AKT) was detected once activated by TERT, and there were increased phosphorylated (p)-AKT protein levels in the rTERT group, and decreased p-AKT protein levels in the siTERT group. In conclusion, TERT could induce thyroid carcinoma cell proliferation mainly through the PTEN/AKT signaling pathway.

\section{Introduction}

Thyroid carcinoma is the most common endocrine malignant tumor in the world, which accounts for $94.5 \%$ of all endocrine tumors. The incidence of thyroid cancer has been increasing since the end of last century and has ranked the top of the list of head and neck cancers $(1,2)$. Papillary thyroid cancer (PTC) is the most common pathology type in thyroid cancer, $\sim 90 \%$ of thyroid carcinoma. 85-90\% incidence of thyroid cancer was caused by PTC. More women are involved in it than men, and most of them are accompanied by cervical lymph node metastasis. PTC is a low-grade malignancy, the main clinical symptoms of which are the slow growth of thyroid mass and multifocal occurrence, tendency of regional lymph nodes metastasis. The prognosis of PTC is good after proper effective treatment, with 5-year survival rate of $95 \%$, and 10 -year survival rate of above $90 \%$ (3). However, some PTC is of high invasion ability, and some of them has the tendency of dedifferentiation to form low-differentiated or non-differentiated cancers and result in the decreasing of survival rate and life quality (4).

The occurrence and development of thyroid cancer is a complicated process including a variety of oncogenes, signaling pathway and aberrant proteins, resulting in abnormal proliferation and mutation. Therefore, study on PTC molecular mechanism will help looking for new biomarkers for PTC early diagnosis, lymph nodes metastasis prediction, treatment and prognosis.

Telomerase is a self-templated reverse transcriptase, containing two subunits of TERC (telomerase RNA component) and TERT (telomerase reverse transcriptase). As the 
core subunit of telomerase, TERT catalyzes TERC reverse transcription to regulate telomerase activity and maintain telomere length (5-7). Over-expression of TERT could promote the proliferation of mesenchymal stem cells, epithelial cells and nerve cells $(8,9)$. For a long time, studies on TERT were mainly focused on its maintaining telomere length function to promote cell proliferation ceaselessly. However, TERT has also been found non-telomere dependent functions in recent years (10-12), including regulating gene expression $(13,14)$, cell signal pathway (15) or cell cycle (16), protecting mitochondrial DNA (17), and regulating DNA injury reaction (18). Researches before discovered that TERT could regulate $>300$ downstream factors, which were related to many kinds of cell signaling, cell proliferation and cell cycle regulation (19).

TERT could regulate cell proliferation and cell cycle by different signal pathways, to excert functions in tumors and different tissues. As important signal pathways, $\mathrm{Rb} / \mathrm{E} 2 \mathrm{~F}, \mathrm{Wnt} / \beta$-catenin, and phosphoinositide 3 -kinase $(\mathrm{PI} 3 \mathrm{~K}) /$ protein kinase $\mathrm{B}$ (AKT) pathways were all reported to be related to TERT regulation in different cells (20). However, the mechanism of TERT function on PTC cells is still not clear now. In order to illuminate the exact molecular mechanism, we performed TERT over-expression and TERT silencing respectively in PTC cells, to study function of TERT on PTC cells proliferation and related signal pathways. It will provide new thoughts for the treatment of PTC.

\section{Materials and methods}

Cell culture. Human PTC K1 cells were used in the present study. Though we lately discovered K1 cells were actually cells mixed with GLAG-66 cells, of the thyroid gland papillary carcinoma, it did not affect studying function of the target gene on PTC, which was verified by numerous researches before (21-30). K1 cells (mixed thyroid gland papillary carcinoma cells) were purchased from ATCC (Guangzhou, China) were cultured in Dulbecco's modified Eagle's medium (DMEM) of 10\% fetal bovine serum (FBS; both Gibco; Thermo Fisher Scientific, Inc., Waltham, MA, USA) and $1 \%$ penicillin/streptomycin (Invitrogen, Carlsbad, CA, USA) at $37^{\circ} \mathrm{C}$ with $5 \% \mathrm{CO}_{2}$. Cells of logarithm phase were used in our research.

Recombined plasmid construction and cell transfection. TERT siRNA (siTERT) sequence was synthesized by Genepharma Company (Shanghai, China). Recombined TERT over-expression plasmid and negative control (NC) were constructed before cell transfection too. siTERT, TERT over-expression plasmid and NC were transfected to mixed thyroid gland papillary carcinoma cells respectively. Briefly, cells were first seeded in 6-well plates at the initial concentration of $5 \times 10^{4}$ cells/well and cultured in DMEM with $10 \%$ FBS and without antibiotic for $24 \mathrm{~h}$, Then, cells were washed by serum-free DMEM twice and cultured for $30 \mathrm{~min}$ in it. When cells were sufficient confluent, they were transfected with siTERT group, recombined TERT plasmid (rTERT group) and NC group by Lipofectamin 2000 (Invitrogen) respectively and cultured for $6 \mathrm{~h}$, according to the manufacturer's instructions. Finally, cells were cultured in 10\% FBS-containing DMEM for another $48 \mathrm{~h}$, and the transfection efficiency was detected by RT-qPCR and western blot.
Table I. Primer sequences used in the present study.

\begin{tabular}{lll}
\hline Name & Type & \multicolumn{1}{c}{ Sequence (5'-3') } \\
\hline$\beta$-actin & Forward & GTGGACATCCGCAAAGAC \\
& Reverse & GAAAGGGTGTAACGCAACT \\
TERT & Forward & CTTCCTCTACTCCTCAGGCG \\
& Reverse & CAAGCAGCTCCAGAAACAGG \\
P27 & Forward & CTCTGAGGACACGCATTTGG \\
& Reverse & GTTTGACGTCTTCTGAGGCC \\
P53 & Forward & GCCCCTCCTCAGCATCTTAT \\
& Reverse & AAAGCTGTTCCGTCCCAGTA \\
PTEN & Forward & ACCCACCACAGCTAGAACTT \\
& Reverse & CGCCTCTGACTGGGAATAGT \\
CDK2 & Forward & GCTTTTGGAGTCCCTGTTCG \\
& Reverse & ACAAGCTCCGTCCATCTTCA \\
Cyclin D1 & Forward & CCCTCGGTGTCCTACTTCAA \\
& Reverse & CTTAGAGGCCACGAACATGC \\
CDC25A & Forward & CTGTTTGACTCCCCTTCCCT \\
& Reverse & GGGGAAGATGCCAGGGATAA
\end{tabular}

TERT, telomerase reverse transcriptase; PTEN, phosphatase and tensin homolog, protein kinase $\mathrm{B}$; CDK, cyclin dependent kinase; CDC25A, cell division cycle 25A.

Methyl thiazolyl tetrazolium (MTT) assay. Cell proliferation of living cells in different groups (Control, NC, siTERT, rTERT) was determined by MTT assay at 24, 48 and $72 \mathrm{~h}$ respectively, according to the manufacturer's protocols (Sigma-Aldrich; Merck KGaA, Darmstadt, Germany). Cells (5x10 $/$ well) and $10 \mu \mathrm{l} 5 \mathrm{mg} / \mathrm{ml}$ MTT reagents were added and mixed in 96-well plates, with the incubation of $4 \mathrm{~h}$ in $5 \% \mathrm{CO}_{2}$-containing incubator at $37^{\circ} \mathrm{C}$. Supernatant was removed and $150 \mu \mathrm{l}$ DMSO was added to dissolve the blue crystals (formazan) to be measured under $490 \mathrm{~nm}$ by microplate reader (Syngene Europe, Cambrige, UK). The higher the OD value was, the more living cells and higher activity existed.

Carboxyfluorescein diacetate succinimidyl ester(CFSE) assay. Cell proliferation of all cells including living cells and dead cells in different groups (Control, NC, siTERT, rTERT) was detected by CSFE cell proliferation kit (Invitrogen), according to the manufacturer's protocols. Cells after $24 \mathrm{~h}$ transfection were resuspended in $1 \mathrm{ml}$ preheating phosphate buffer solution (PBS) in sterile centrifuge tubes, at the final concentration of $1 \times 10^{6} / \mathrm{ml} .2 \mu \mathrm{l} \mathrm{CFSE} \mathrm{(5} \mathrm{mM)} \mathrm{stocking} \mathrm{reagent} \mathrm{was} \mathrm{added} \mathrm{into}$ cell suspension to the final concentration of $10 \mu \mathrm{M}$, and incubated for $10 \mathrm{~min}$ at $37^{\circ} \mathrm{C}$ after sufficient mixing. Then cells were cultured in $10 \mathrm{ml}$ icy DMEM with $10 \%$ bovine serum for $5 \mathrm{~min}$ on ice in the dark. After centrifuged for $7 \mathrm{~min}$ at 1,000 rpm, cells were suspended and washed in $5 \mathrm{ml}$ DMEM containing $10 \%$ bovine serum for two times. After that, cells were inoculated in 24 -well plates $\left(1 \times 10^{5} /\right.$ cell) and incubated with $5 \% \mathrm{CO}_{2}$ at $37^{\circ} \mathrm{C}$. After being washed with PBS for two times, cells were digested, collected and detected by flow 
A

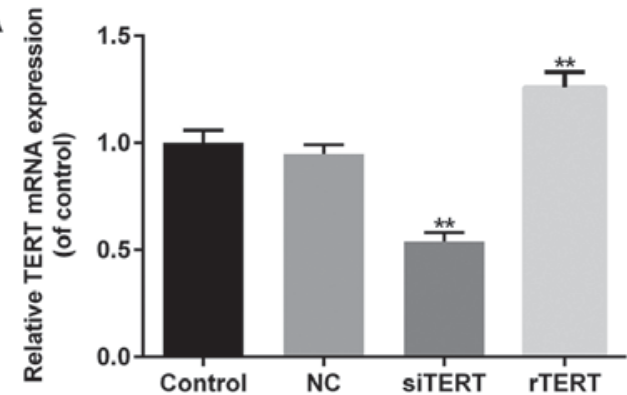

B

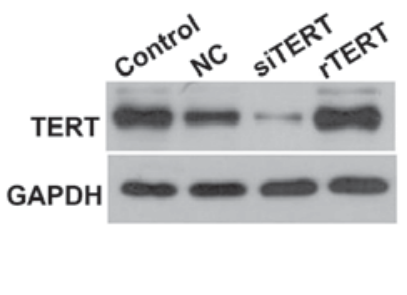

C

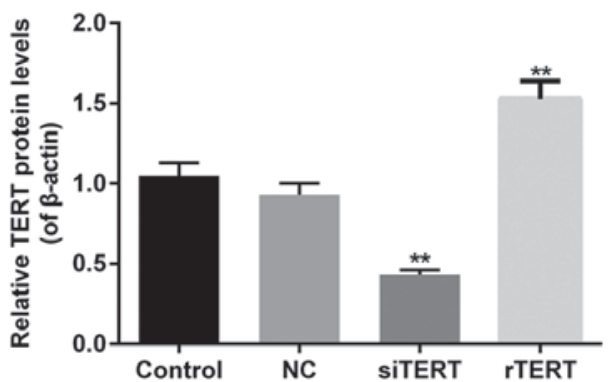

Figure 1. Transfection efficiency of TERT in mixed-PTC cells. (A) Reverse transcription-quantitative polymerase chain reaction was performed to detect the mRNA expression of TERT. TERT expression increased significantly in rTERT group, and decreased significantly in siTERT. (B) Western blotting was performed to detect the protein levels of TERT. (C) TERT protein expression increased significantly in the rTERT group, and decreased significantly in siTERT group, when compared with te NC group. There was no significant difference of TERT expression between NC and control group. Data were presented as mean \pm standard deviation ( $\mathrm{n}=3$ ). ${ }^{* * *} \mathrm{P}<0.01$ vs. NC. TERT, telomerase reverse transcriptase; rTERT, recombined TERT plasmid (overexpression group); siTERT, TERT small interfering RNA (interfering group); NC, negative control.

cytometer (BD Biosciences, Franklin Lakes, NJ, USA), with the whole process avoiding light.

Cell cycle analysis. Cell cycle status in different groups (Control, NC, siTERT, rTERT) was measured by propidium iodide (PI) staining after cell transfection. Cells after $24 \mathrm{~h}$ transfection were trypsinized, washed twice using PBS and fixed by ice-cold $70 \%$ ethanol for $4 \mathrm{~h}$. After being washed twice with PBS, $400 \mu 1$ PI was added in and incubated for $30 \mathrm{~min}$ reaction at room temperature. Thereafter, cell cycle status was immediately measured by flow cytometer (BD Biosciences). The proportion of cells in G0/G1, S and G2/M phases was detected.

Reverse transcription-quantitative polymerase chain reaction $(R T-q P C R)$. Total RNA was extracted from different cell groups (Control, NC, siTERT, rTERT) respectively, and cDNA was acquired using a first strand cDNA kit (Sigma-Aldrich; Merck KGaA), according to the manufacturer's protocols. PCR amplification process included: predenaturation at $95^{\circ} \mathrm{C}$ for $30 \mathrm{sec}$, followed by 40 cycles reaction: Denaturation at $95^{\circ} \mathrm{C}$ for $5 \mathrm{sec}$, annealing/extension at $60^{\circ} \mathrm{C}$ for $30 \mathrm{sec}$ in ABI 7300 Thermocycler using the SYBR-Green Master Mix (Applied Biosystems; Thermo Fisher Scientific Inc.). The primer sequences were displayed in Table I.

Western blot analysis. Total proteins were extracted from different cell groups (Control, NC, siTERT, rTERT). The concentrations of proteins were determined by BCA assay. Then proteins were separated by sodium dodecyl sulfate-polyacrylamide gel electrophoresis (SDS-PAGE) and electroblotted to a polyvinylidene fluoride membrane (PVDF; GE Healthcare, Life Sciences, Little Chalfont, UK). After being blocked by $5 \%$ nonfat dry milk, the membranes were reacted with specific primary antibodies respectively overnight at $4^{\circ} \mathrm{C}$, including: rabbit anti-TERT (ab191523; 1:1,000), anti-P27 KIP1 (ab75908; 1:1,000), anti-P53 (ab38497; 1:1,000), anti-PTEN (ab31392; 1:1,000), anti-CDK2 (ab32147; 1:5,000), anti-Cyclin D1 (ab226977; 1:5,000), anti-CDC25A (ab75743; 1:1,000), anti- $\beta$-catenin (ab16051; 1:4,000), anti-Rb (ab47763; 1:1,000), anti-p-AKT (ab38449; 1:1,000), anti-AKT (ab18785; $1: 1,000)$ and anti- $\beta$-actin (ab8227; 1:2,000; loading control). then they were conjugated with the appropriate HRP-conjugated secondary antibodies (ab205718; 1:5,000; all Abcam, Cambridge, UK). The PVDF membranes were exposed to X-ray film and detected by adding enhanced chemiluminescense (ECL) reagent (GE Healthcare, Life Sciences,). Lab Works Image Acquisition and Analysis Software (UVP, Inc., Upland, CA, USA) were used to quantify band intensities.

Statistical analysis. Data were expressed as mean \pm standard deviations of three independent experiments. Statistical analysis was conducted by SPSS 22.0 statistical software (IBM Corp., Armonk, NY, USA). Differences were analyzed by one-way analysis of variance and a Tukey test. $\mathrm{P}<0.05$ was considered to indicate a statistically significant difference.

\section{Results}

The transfection efficiency of TERT over-expression and interference in mixed PTC cells. RT-qPCR and western blot were performed to detect TERT transfection efficiency in different groups of mixed PTC cells. It showed that both mRNA and protein levels of TERT increased significantly in rTERT group, and decreased significantly in siTERT group $(\mathrm{P}<0.05)$, compared with NC group. Besides, there was no significant difference of TERT expression between NC and control groups $(\mathrm{P}>0.05)$ (Fig. 1).

TERT promoted cell proliferation in mixed PTC cells. Cell proliferation of living cells after transfection is determined by MTT assay, because the NADP-related dehydrogenases in mitochondria of living cells could reduce yellow MTT to blue crystal. Hence dead cells couldn't be detected by MTT for lacking of these dehydrogenases. However, CFSE assay can detect not only living cells, but also cells having divided and died. It attributes to the evenly distribution of CFSE fluorescence when CFSE labeled cells divide to two daughter cells. The fluorescence intensity remains the same level in a few days after division to help fully analyzing cell proliferation.

The results of MTT indicated that TERT over-expression significantly promoted cell proliferation of mixed PTC cells in time-dependent manners (24, 48 and $72 \mathrm{~h})$, compared 
A

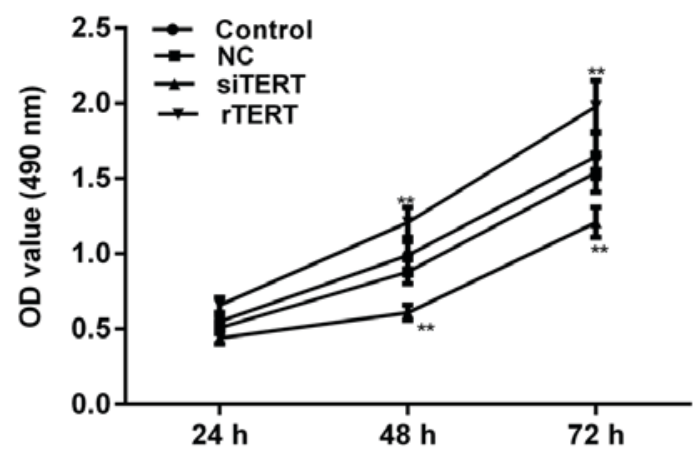

C

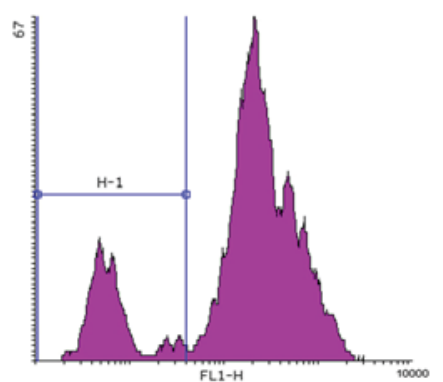

Control

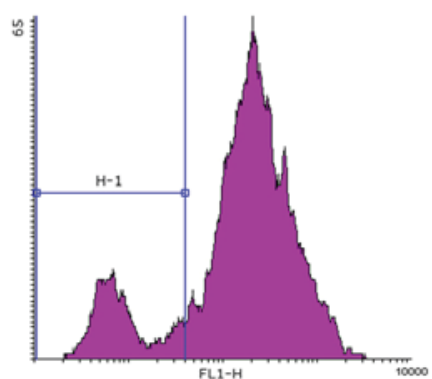

NC
B
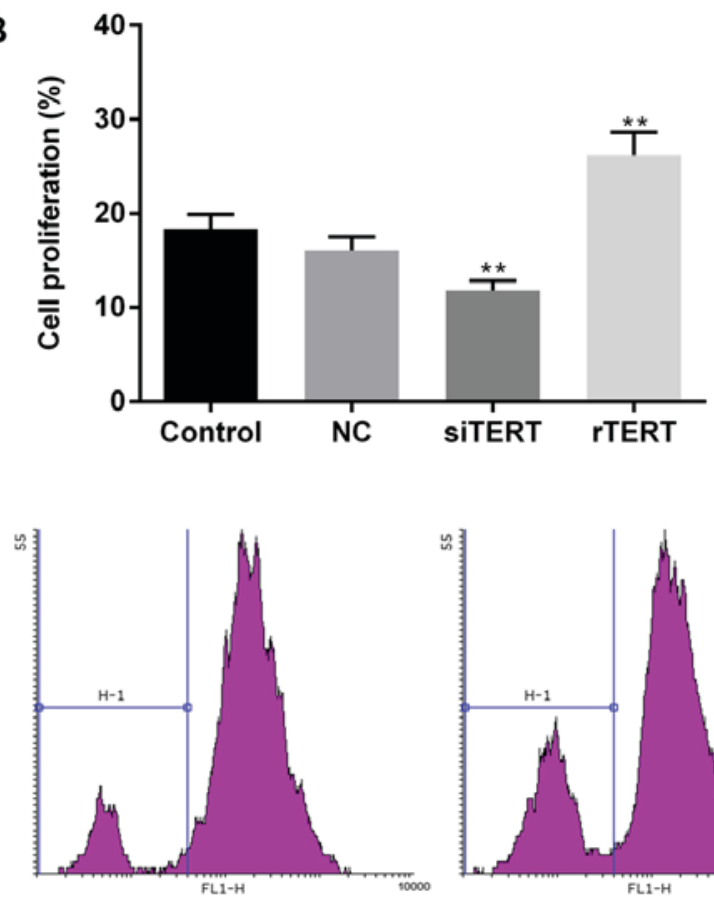

SITERT

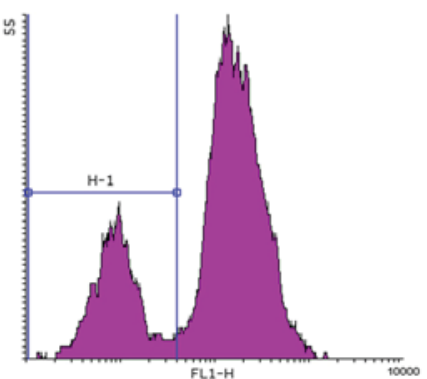

rTERT

Figure 2. TERT promoted the cell proliferation of mixed-PTC cells. (A) MTT assay was performed to detect the living cell proliferation of mixed-PTC cells. It was indicated that TERT overexpression significantly promoted cell proliferation, and TERT interference markedly inhibited it in time-dependent manner. Cell activity of NC group was not statistically different with the control group. (B) Carboxyfluorescein diacetate succinimidyl ester was used to detect all cell proliferation. (C) The flow cytometry results revealed that, cell proliferation decreased significantly in the siTERT group, and increased significantly in rTERT group. Cell activity of the NC group was not statistically different with the control group. Data were presented as mean \pm standard deviation (n=3). ${ }^{* *} \mathrm{P}<0.01$ vs. NC. TERT, telomerase reverse transcriptase; rTERT, recombined TERT plasmid (overexpression group); siTERT, TERT small interfering RNA (interfering group); NC, negative control; PTC, papillary thyroid cancer; OD, optical density.

with NC group $(\mathrm{P}<0.05)$. Cell activity of $\mathrm{NC}$ group was of no statistically difference with control group ( $\mathrm{P}>0.05)$. The living cell number in rTERT group was significantly higher than $\mathrm{NC}$ and control group after transfection for $24 \mathrm{~h}$. At the same time, TERT interference dramatically inhibited cell proliferation of mixed PTC cells in time-dependent manners (24, 48 and $72 \mathrm{~h}$ ), compared with $\mathrm{NC}$ and control groups $(\mathrm{P}<0.05)$. The living cell numbers in siTERT group were significantly lower than NC and control groups after transfection for $24 \mathrm{~h}$ (Fig. 2A).

CFSE was used to verify these results after $24 \mathrm{~h}$ of transfection. The results of flow cytometry showed that, M1 value decreased significantly in siTERT group, compared with NC group $(\mathrm{P}<0.05)$, which represented TERT interference inhibited cell proliferation of mixed PTC cells. The M1 value of rTERT group increased significantly, compared to NC group $(\mathrm{P}<0.05)$, meaning TERT over-expression promoted cell proliferation of mixed PTC cells (Fig. 2B, C).

TERT promoted cell cycle progression in mixed PTC cells. PI was used to determine cell cycle progression of different cells. More cells of siTERT group stayed in G1 phase, and less cells stayed in S and G2 phases, compared with $\mathrm{NC}$ and control groups $(\mathrm{P}<0.05)$. The results showed that TERT interference could inhibit cell proliferation of mixed PTC cells by blocking cell cycle from G1/S transition. Otherwise, less cells in G1 phase and more cells in S and G2 phases were observed in rTERT group than $\mathrm{NC}$ and control groups $(\mathrm{P}<0.05)$, which indicated that TERT promoted cell proliferation of mixed PTC cells by accelerating cell cycle progression (Fig. 3).

TERT promoted cell cycle progression by regulating expression levels of cell cycle related factors in mixed PTC cells. RT-qPCR and western blot were conducted to detect cell cycle related factors expression in different groups. The expression levels of P27, P53 and PTEN decreased significantly in rTERT group and increased significantly in siTERT group, both in mRNA and protein manners $(\mathrm{P}<0.05)$. The expression levles of CDK2 and Cyclin D1 increased significantly in rTERT group and decreased significantly in TERT silencing group, both in mRNA and protein manners $(\mathrm{P}<0.05)$. The expression level of CDC25A didn't change too much in different groups, both in mRNA and protein manners ( $\mathrm{P}>0.05$ ) (Fig. 4).

TERT promoted cell cell proliferation by activating AKT signaling pathway in mixed PTC cells. As P27 and P53 were the upstream factors of Rb pathway, Cyclin D1 was the critical regulator and effector of $\mathrm{Rb}$ and $\mathrm{Wnt} / \beta$-catenin pathway, and PTEN inactivation could abnormally activate PI3K/AKT pathway, we further detected function of TERT on Rb, $\beta$-catenin, AKT and phosphorylated AKT (p-AKT) in PTC cells. Results showed that the protein levels of p-AKT increased significantly in rTERT group and decreased significantly in siTERT group $(\mathrm{P}<0.05)$, with no significant change on total AKT protein expression $(\mathrm{P}>0.05)$. However, the protein levels of $\mathrm{Rb}$ and $\beta$-catenin had no significant change 

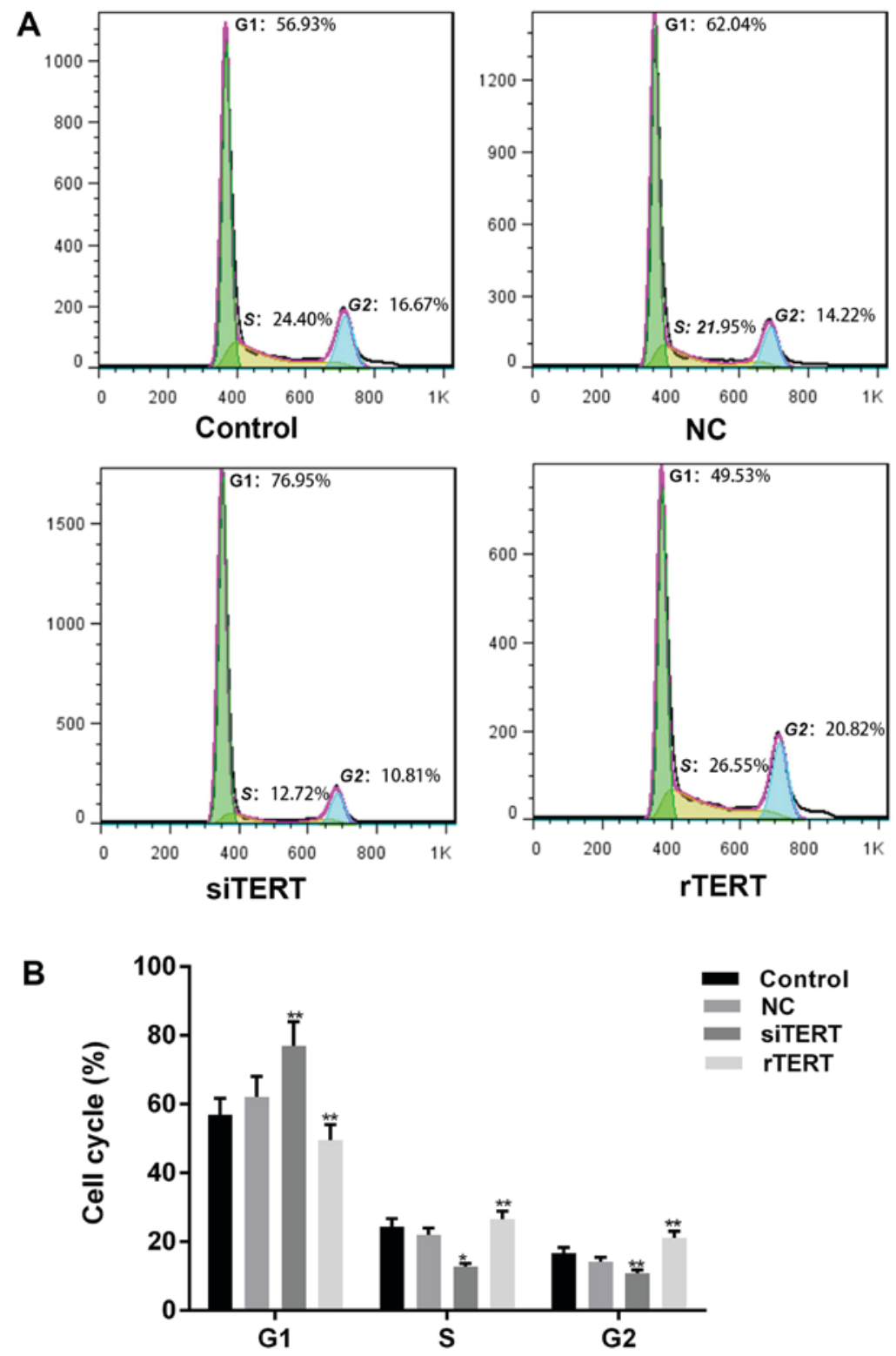

Figure 3. TERT promoted cell cycle progression of mixed-PTC cells. (A) Propidium iodide was used to determine the cell cycle progression of different cells. (B) It demonstrated that TERT interference inhibited the cell proliferation of mixed-PTC cells by blocking the cell cycle from G1/S transition, and TERT overexpression promoted cell proliferation by accelerating cell cycle progression, when compared with the NC group. Cell cycle progression of the NC group was not statistically different with the control group. Data were presented as mean \pm standard deviation $(n=3)$. $P<0.05$ and ${ }^{* *} \mathrm{P}<0.01$ vs. NC. TERT, telomerase reverse transcriptase; rTERT, recombined TERT plasmid (overexpression group); siTERT, TERT small interfering RNA (interfering group); NC, negative control; PTC, papillary thyroid cancer.

both in rTERT and siTERT groups, compared with NC and control groups $(\mathrm{P}>0.05)$ (Fig. 5).

\section{Discussion}

Thyroid carcinoma is the most common endocrine malignant tumor in the world, and the incidence has ranked top of the list of head and neck cancers. The development of thyroid cancer is a complex process including many signaling pathways, with abnormal cell proliferation.

Except maintaining telomere length, TERT has also been found non-telomere dependent functions including cell signal pathway or cell cycle regulation and so on. Previous researchers found that over-expression of TERT could promote the proliferation of many cells like epidermal hair follicle stem cells in mice, without significant telomere extension observed (31). But whether and how TERT effect on PTC cells still needs further research.

In our study, we used liposome transfection to acquire TERT over-expression and TERT silencing PTC cells (actually mixed thyroid gland papillary carcinoma cells) successfully. RT-qPCR and western blot were performed to detect TERT levels significantly promoted in TERT over-expressed cells, and dramatically decreased in TERT silencing cells, verifying good transfection effect. Then function of TERT on cell proliferation of mixed PTC cells was evaluated. MTT assay detected living cells proliferation, while CFSE assay determined all cells including living cells and dead cells proliferation. It indicated that TERT could promote cell proliferation of mixed PTC cells, for not only living cells but 
A

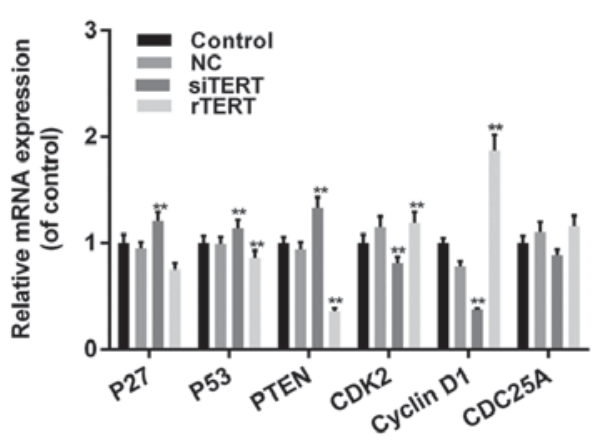

B

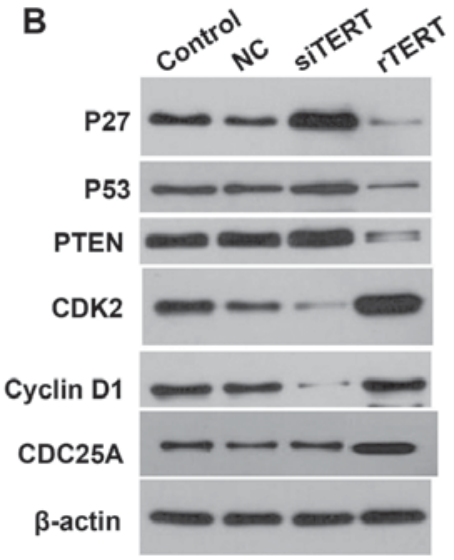

C

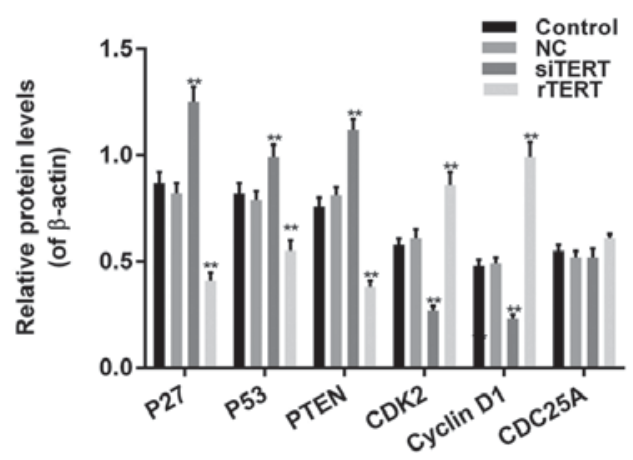

Figure 4. Expression of TERT regulated cell cycle associated factors in mixed-papillary thyroid cancer cells. (A) Reverse transcription-quantitative polymerase chain reaction and (B) western blotting were conducted to detect the expression of cell cycle associated factors in different groups. (C) Relative protein expression. Data were presented as mean \pm standard deviation $(n=3) .{ }^{* *} \mathrm{P}<0.01$ vs. NC. TERT, telomerase reverse transcriptase; rTERT, recombined TERT plasmid (overexpression group); siTERT, TERT small interfering RNA (interfering group); NC, negative control; PTEN, phosphatase and tensin homolog, protein kinase B; CDK, cyclin dependent kinase; CDC25A, cell division cycle 25A.

A

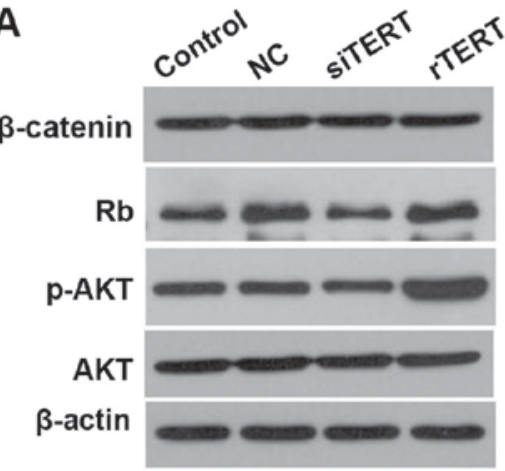

B

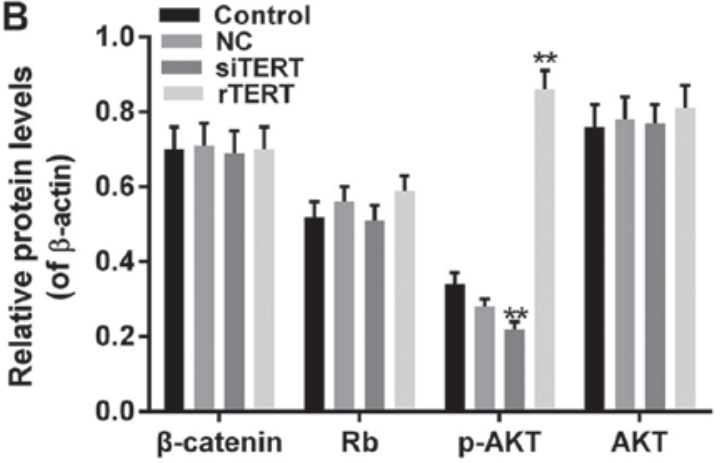

Figure 5. TERT regulates the AKT signaling pathway in mixed-papillary thyroid cancer cells. (A) Western blotting was performed to evaluate the (B) protein levels of $\mathrm{Rb}, \beta$-catenin $\mathrm{p}$-AKT and AKT. Data were presented as mean \pm standard deviation $(\mathrm{n}=3){ }^{*}{ }^{* *} \mathrm{P}<0.01 \mathrm{vs}$. NC. TERT, telomerase reverse transcriptase; rTERT, recombined TERT plasmid (overexpression group); siTERT, TERT small interfering RNA (interfering group); NC, negative control; p-, phosphorylated; AKT, protein kinase B; $\mathrm{Rb}$, retinoblastoma.

also dead cells proliferation was detected promoted by TERT over-expression, and inhibited by TERT silencing in mixed PTC cells.

More cells in S and G2 phases and fewer cells in G1 phase were observed by flow cytometer in TERT over-expressed cells, meaning more cells went into cell cycle to promote cell proliferation of mixed PTC cells. Otherwise, TERT silencing could block cell cycle at G1/S transition. It indicated that TERT accelerated cell proliferation by causing more cells into cell cycle progression, while TERT silencing inhibited cell proliferation by inducing cell cycle arrestment. Thereafter, RT-qPCR and western blot were conducted to detect the expression changes of cell cycle and proliferation related factors, to preliminarily illustrate the mechanism of TERT promoting cell proliferation and cell cycle progression of mixed PTC cells.

Cell cycle dependent proteins have special functions in the terminal differentiation of eukaryotic cells and the regulation of cell cycle. They play a dual role in maintaining cell cycle progression and keeping cells in a stationary phase after mitosis. Cell cycle progression is regulated by cyclin dependent kinases (CDKs). The activity of CDKs is also mediated by positive regulators such as Cyclin D1 (32-34) and CDK inhibitors (CDKIs) including retinoblastoma protein $(\mathrm{Rb})$ and $\mathrm{Rb}$ upstream molecules like P27 and P53. Phosphatase and tensin homolog (PTEN) was reported to downregulate the expression of P27 to promote cell proliferation (35). Cyclin D1 is a critical positive regulating factor in cell cycle on $\mathrm{G} 1$ phase progression. The activation of Cyclin D1 could accelerate G1/S transition by promoting downstream gene expression $(36,37)$. Increased Cyclin D1 is reported in many tumors like hepatocarcinoma cell and so on (38). Our study showed that TERT could modulate cell proliferation of mixed PTC cells by positive regulating Cyclin D1 expression. Cell division cycle 25A (CDC25A) play important roles to fully activate CDKs, by removing the inhibitory phosphorylation on CDKs. But the expression of CDC25A was of no significant differences among TERT over-expression or silencing mixed-PTC cells.

Otherwise, gene mutation induces the downregulation of cancer gene suppressor and abnormal persistent activation of some signaling pathways, including MAPK signaling pathway, Wnt/ $\beta$-catenin, and PI3K/AKT pathway and so on, which induce tumor development, invasion, metastasis and recurrence. P53 gene point mutation and Wnt/ $\beta$-catenin 
activation are considered the definite markers of PTC transition from differentiated to undifferentiated carcinoma (39-41). P27 or P53-coding transcription factors significantly regulate some cell functions of great importance, such as cell growth, proliferation, cell cycle, apoptosis and DNA repairing and so on. P27 inhibit cell cycle transition from G1 to $\mathrm{S}$ phage by inhibiting the activation of CDKs $(42,43)$. P53 gene point mutation makes it lose tumor suppressor function and is involved in the initiation of multiple tumors (44). P53 inactivation often occurs in late stages of thyroid cancer or poorly differentiated pathological thyoid cancer $(44,45)$, and promotes cell proliferation and persistently differentiate. In our study, P27 and P53 decreased significantly in TERT over-expressed mixed-PTC cells and increased in TERT interfering cells. It indicated TERT promoted cell proliferation of mixed PTC cells in a way of inactivating P27 and P53. As P27 and P53 are the upstream factors of Rb pathway, and Cyclin D1 is the critical regulator and effector of $\mathrm{Rb}$ and $\mathrm{Wnt} / \beta$-catenin pathway, we further detected function of TERT on $\mathrm{Rb}$ and $\beta$-catenin expression in mixed PTC cells. $\mathrm{Rb}$ is the first found tumor suppressor gene in human, also a negative cell cycle regulatory factor. It is considered to be the main regulator of all tissue cell growth and development, even cancer occurrence. $\mathrm{Rb}$ can prevent cell cycle progression, promote cell differentiation, and inhibit cell over-growth, which depends on its interaction with transcription factor E2F and DP (45). However, both over-expression or interference of TERT were found nothing to do with $\mathrm{Rb}$ expression, indicating TERT had no effect on $\mathrm{Rb}$ to regulate PTC cell proliferation. The abnormal activation of $\mathrm{Wnt} / \beta$-catenin pathway could induce endothelium tumor development. As a cytoplasmic protein, $\beta$-catenin plays important roles in cell adherence to induce epithelial-mesenchymal transition. Though function of $\beta$-catenin as promoting thyroid tumor proliferation and dedifferentiation is definite (46), further researches are needed for the mechanism of it in early stage of thyroid carcinoma. In our study, $\beta$-catenin was found of no relationship with TERT involved thyroid carcinoma development mechanism, even when TERT over-expressed or interfered.

PI3K/AKT signaling pathway is the critical way of regulating cell growth and proliferation (47). The abnormal activation of PI3K/AKT pathway participates in tumor formation of thyroid carcinoma. The activation of AKT could stimulate PI3K/AKT pathway to phosphorylate and activate mTOR to regulate cell growth critical factors translation like Cyclin D1 and so on, so to regulate cell growth and proliferation. PTEN participated in inhibiting PI3K/AKT signaling pathway as a cancer suppressor gene, which could inhibit tumor cell proliferation, metastasis and invasion. Researches before found that PTEN inactivation and RAS persistent activation were also the reason of PI3K/AKT abnormal activation in thyroid carcinoma. In our study, PTEN expression was found significantly downregulated in TERT over-expressed cells, and upregulated in TERT interfering cells. $\mathrm{p}$ - and activated AKT were detected increased significantly in TERT over-expressed cells, and decreased in TERT interfering cells. It definitely demonstrated that TERT regulated cell proliferation of mixed-PTC cells through PTEN/AKT pathway.

In conclusion, our study preliminarily illustrated the mechanism of TERT promoting cell proliferation and cell cycle progression of mixed PTC cells, which mainly functioned through PTEN/AKT pathway. Though it is a pity that the PTC K1 cell line used in this study is mixed with thyroid gland papillary carcinoma cells, it still provides a novel molecular target for thyroid carcinoma diagnosis, treatment and prognosis.

\section{Acknowledgements}

Not applicable.

\section{Funding}

No funding was received.

\section{Availability of data and materials}

The analysed datasets generated during the study are available from the corresponding author on reasonable request.

\section{Authors' contributions}

NH conceived the research. HZ performed the experiments and wrote the paper. All authors have read and approved the final manuscript.

\section{Ethics approval and consent to participate}

Not applicable.

\section{Consent for publication}

Not applicable.

\section{Competing interests}

The authors declare that they have no competing interests.

\section{References}

1. Davies L and Welch HG: Increasing incidence of thyroid cancer in the United States, 1973-2002. JAMA 295: 2164-2167, 2006.

2. Wang Y and Wang W: Increasing incidence of thyroid cancer in Shanghai, China, 1983-2007. Asia Pac J Public Health 27: NP223-NP229, 2015.

3. Albores-Saavedra J, Henson DE, Glazer E and Schwartz AM: Changing patterns in the incidence and survival of thyroid cancer with follicular phenotype-papillary, follicular, and anaplastic: A morphological and epidemiological study. Endocr Pathol 18: 1-7, 2007.

4. Wynford-Thomas D: Origin and progression of thyroid epithelial tumours: Cellular and molecular mechanisms. Horm Res 47: 145-157, 1997.

5. Gomez DE, Armando RG, Farina HG, Menna PL, Cerrudo CS, Ghiringhelli PD and Alonso DF: Telomere structure and telomerase in health and disease (review). Int J Oncol 41: 1561-1569, 2012.

6. Beier F, Foronda M, Martinez P and Blasco MA: Conditional TRF1 knockout in the hematopoietic compartment leads to bone marrow failure and recapitulates clinical features of dyskeratosis congenita. Blood 120: 2990-3000, 2012.

7. Autexier $\mathrm{C}$ and Lue NF: The structure and function of telomerase reverse transcriptase. Annu Rev Biochem 75: 493-517, 2006.

8. Cohen $\mathrm{H}$ and Sinclair DA: Recombination-mediated lengthening of terminal telomeric repeats requires the Sgs1 DNA helicase. Proc Natl Acad Sci USA 98: 3174-3179, 2001 
9. Sarin KY, Cheung P, Gilison D, Lee E, Tennen RI, Wang E, Artandi MK, Oro AE and Artandi SE: Conditional telomerase induction causes proliferation of hair follicle stem cells Nature 436: 1048-1052, 2005.

10. Smith LL, Coller HA and Roberts JM: Telomerase modulates expression of growth-controlling genes and enhances cell proliferation. Nat Cell Biol 5: 474-479, 2003.

11. Cong Y and Shay JW: Actions of human telomerase beyond telomeres. Cell Res 18: 725-732, 2008.

12. Allsopp RC, Morin GB, DePinho R, Harley CB and Weissman IL: Telomerase is required to slow telomere shortening and extend replicative lifespan of HSCs during serial transplantation. Blood 102: 517-520, 2003.

13. Kirkpatrick KL, Newbold RF and Mokbel K: The mRNA expression of hTERT in human breast carcinomas correlates with VEGF expression. J Carcinog 3: 1, 2004.

14. Sharma GG, Gupta A, Wang H, Scherthan H, Dhar S, Gandhi V, Iliakis G, Shay JW, Young CS and Pandita TK: hTERT associates with human telomeres and enhances genomic stability and DNA repair. Oncogene 22: 131-146, 2003.

15. Ghosh A, Saginc G, Leow SC, Khattar E, Shin EM, Yan TD, Wong M, Zhang Z, Li G, Sung WK, et al: Telomerase directly regulates $\mathrm{NF}-\kappa \mathrm{B}$-dependent transcription. Nat Cell Biol 14 $1270-1281,2012$

16. Xiang H, Wang J, Mao Y, Liu M, Reddy VN and Li DW: Human telomerase accelerates growth of lens epithelial cells through regulation of the genes mediating RB/E2F pathway. Oncogene 21: 3784-3791, 2002.

17. Ahmed S, Passos JF, Birket MJ, Beckmann T, Brings S, Peters H, Birch-Machin MA, von Zglinicki T and Saretzki G: Telomerase does not counteract telomere shortening but protects mitochondrial function under oxidative stress. J Cell Sci 121: 1046-1053, 2008.

18. Lee J, Sung YH, Cheong C, Choi YS, Jeon HK, Sun W, Hahn WC, Ishikawa F and Lee HW: TERT promotes cellula and organismal survival independently of telomerase activity. Oncogene 27: 3754-3760, 2008.

19. Perrault SD, Hornsby PJ and Betts DH: Global gene expression response to telomerase in bovine adrenocortical cells. Biochem Biophys Res Commun 335: 925-936, 2005

20. Wu XQ, Huang C, He X, Tian YY, Zhou DX, He Y, Liu XH and Li J: Feedback regulation of telomerase reverse transcriptase: New insight into the evolving field of telomerase in cancer. Cell Signal 25: 2462-2468, 2013.

21. Cheng L, Jin Y, Liu M, Ruan M and Chen L: HER inhibitor promotes BRAF/MEK inhibitor-induced redifferentiation in papillary thyroid cancer harboring BRAFV600E. Oncotarget 8: 19843-19854, 2017.

22. Kolanowska M, Wójcicka A, Kubiak A, Świerniak M, Kotlarek M, Maciag M, Gaj P, Koperski Ł, Górnicka B and Jażdżewski K: Functional analysis of a novel, thyroglobulin-embedded microRNA gene deregulated in papillary thyroid carcinoma. Sci Rep 7: 9942, 2017.

23. Li W, Huang Q, Sun D, Zhang G and Tan J: RDM1 gene overexpression represents a therapeutic target in papillary thyroid carcinoma. Endocr Connect 6: 700-707, 2017.

24. Liu J, Sun W, Dong W, Wang Z, Qin Y, Zhang T and Zhang H: HSP90 inhibitor NVP-AUY922 induces cell apoptosis by disruption of the survivin in papillary thyroid carcinoma cells. Biochem Biophys Res Commun 487: 313-319, 2017.

25. Liu K, Huang W, Yan DQ, Luo Q and Min X: Overexpression of long intergenic noncoding RNA LINC00312 inhibits the invasion and migration of thyroid cancer cells by down-regulating microRNA-197-3p. Biosci Rep 37: pii: BSR20170109, 2017.

26. Ni J, Wang F, Yue L, Xiang GD, Zhao LS, Wang Y, Ye LZ and Dong J: The effects and mechanisms of berberine on proliferation of papillary thyroid cancer K1 cells induced by high glucose. Zhonghua Nei Ke Za Zhi 56: 507-511, 2017 (In Chinese).

27. Stasiołek M, Adamczewski Z, Śliwka PW, Puła B, Karwowski B Merecz-Sadowska A, Dedecjus $M$ and Lewiński A: The molecular effect of diagnostic absorbed doses from 131I on papillary thyroid cancer cells in vitro. Molecules 22: pii: E993, 2017.

28. Yang D, Wang C, Luo Y, Li X, Song Q, Zhang J and Xin S: Activated E2F activity induces cell death in papillary thyroid carcinoma K1 cells with enhanced Wnt signaling. PLoS One 12: e0178908, 2017.
29. Yin Y, Hong S, Yu S, Huang Y, Chen S, Liu Y, Zhang Q, Li Y and Xiao H: MiR-195 inhibits tumor growth and metastasis in papillary thyroid carcinoma cell lines by targeting CCND1 and FGF2. Int J Endocrinol 2017: 6180425, 2017.

30. Zhang MM, Sun F, Cui B, Zhang LL, Fang Y, Li Y, Zhang RJ, Ye XP, Ma YR, Han B and Song HD: Tumor-suppressive function of UNC5D in papillary thyroid cancer. Oncotarget 8: 96126-96138, 2017.

31. Flores I, Cayuela ML and Blasco MA: Effects of telomerase and telomere length on epidermal stem cell behavior. Science 309: 1253-1256, 2005.

32. Malgrange B, Belachew S, Thiry M, Nguyen L, Rogister B, Alvarez ML, Rigo JM, Van De Water TR, Moonen G and Lefebvre PP: Proliferative generation of mammalian auditory hair cells in culture. Mech Dev 112: 79-88, 2002

33. Chen J, Wang F, Gao X, Zha D, Xue T, Cheng X, Zhong C, Han Y and Qiu J: Decreased level of cyclin A2 in rat cochlea development and cochlear stem cell differentiation. Neurosci Lett 453 166-169, 2009

34. Laine H, Sulg M, Kirjavainen A and Pirvola U: Cell cycle regulation in the inner ear sensory epithelia: Role of cyclin D1 and cyclin-dependent kinase inhibitors. Dev Biol 337: 134-146, 2010.

35. Sun C, Zhao J, Jin Y, Hou C, Zong W, Lu T, Li H and Gao J: PTEN regulation of the proliferation and differentiation of auditory progenitors through the PTEN/PI3K/Akt-signaling pathway in mice. Neuroreport 25: 177-183, 2014.

36. Cattani P, Hohaus S, Bellacosa A, Genuardi M, Cavallo S, Rovella V, Almadori G, Cadoni G, Galli J, Maurizi M, et al: Association between cyclin D1 (CCND1) gene amplification and human papillomavirus infection in human laryngeal squamous cell carcinoma. Clin Cancer Res 4: 2585-2589, 1998.

37. Calbó J, Parreño M, Sotillo E, Yong T, Mazo A, Garriga J and Grana X: G1 cyclin/cyclin-dependent kinase-coordinated phosphorylation of endogenous pocket proteins differentially regulates their interactions with $\mathrm{E} 2 \mathrm{~F} 4$ and gene expression. J Biol Chem 277: 50263-50274, 2002.

38. Schmidt VA, Chiariello CS, Capilla E, Miller F and Bahou WF: Development of hepatocellular carcinoma in Iqgap2-deficient mice is IQGAP1 dependent. Mol Cell Biol 28: 1489-1502, 2008.

39. Omur O and Baran Y: An update on molecular biology of thyroid cancers. Crit Rev Oncol Hematol 90: 233-252, 2014.

40. Li X, Wang Z, Liu J, Tang C, Duan C and Li C: Proteomic analysis of differentially expressed proteins in normal human thyroid cells transfected with PPFP. Endocr Relat Cancer 19: 681-694, 2012

41. Cahill S, Smyth P, Finn SP, Denning K, Flavin R, O'Regan EM, Li J, Potratz A, Guenther SM, Henfrey R, et al: Effect of ret/PTC 1 rearrangement on transcription and post-transcriptional regulation in a papillary thyroid carcinoma model. Mol Cancer 5: 70, 2006.

42. Gardner LB, Li Q, Park MS, Flanagan WM, Semenza GL and Dang CV: Hypoxia inhibits G1/S transition through regulation of p27 expression. J Biol Chem 276: 7919-7926, 2001.

43. Kuo MY, Hsu HY, Kok SH, Kuo RC, Yang H, Hahn LJ and Chiang CP: Prognostic role of p27(Kip1) expression in oral squamous cell carcinoma in Taiwan. Oral Oncol 38: 172-178, 2002.

44. Donghi R, Longoni A, Pilotti S, Michieli P, Della Porta G and Pierotti MA: Gene p53 mutations are restricted to poorly differentiated and undifferentiated carcinomas of the thyroid gland. J Clin Invest 91: 1753-1760, 1993.

45. Kim CS and Zhu X: Lessons from mouse models of thyroid cancer. Thyroid 19: 1317-1331, 2009.

46. Miyake N, Maeta H, Horie S, Kitamura Y, Nanba E, Kobayashi K and Terada T: Absence of mutations in the beta-catenin and adenomatous polyposis coli genes in papillary and follicular thyroid carcinomas. Pathol Int 51: 680-685, 2001

47. Mian C, Barollo S, Pennelli G, Pavan N, Rugge M, Pelizzo MR, Mazzarotto R, Casara D, Nacamulli D, Mantero F, et al: Molecular characteristics in papillary thyroid cancers (PTCs) with no 131I uptake. Clin Endocrinol (Oxf) 68: 108-116, 2008.

This work is licensed under a Creative Commons Attribution-NonCommercial-NoDerivatives 4.0 International (CC BY-NC-ND 4.0) License. 